\title{
DETERMINAN KARAKTERISTIK PERUSAHAAN TERHADAP ENVIRONMENTAL DISCLOSURE (Studi Kasus pada Perusahaan Manufaktur yang Terdaftar di BEI Tahun 2012-2016)
}

\author{
Puji Nurhayati ${ }^{1}$ Sari Kurniati ${ }^{2}$ \\ ${ }^{1}$ Universitas PGRI Madiun \\ nurhayatipuji90@gmail.com \\ ${ }^{2}$ Universitas Islam Batik Surakarta \\ arikade2003@gmail.com
}

\begin{abstract}
This study aims to examine the influence of company characteristics which include profitability, leverage and company size on environmental disclosure. The data used in this study is secondary data with the number of 270 manufacturing companies listed on the Indonesia Stock Exchange in 2012-2016. Data testing uses multiple regression through SPSS software. The test results prove that the profitability and size of the company affect environmental disclosure while leverage does not affect environmental disclosure.
\end{abstract}

Keywords: profitability, leverage, company size, environmental disclosure.

\begin{abstract}
Abstrak
Penelitian ini bertujuan untuk menguji pengaruh karakteristik perusahaan yang meliputi profitabilitas, leverage dan ukuran perusahaan terhadap environmental disclosure. Data yang digunakan dalam penelitian ini adalah data sekunder dengan jumlah 270 perusahaan manufaktur yang terdaftar di Bursa Efek Indonesia tahun 2012 -2016. Pengujian data menggunakan regresi berganda melalui software SPSS. Hasil pengujian membuktikan bahwa profitabilitas dan ukuran perusahaan berpengaruh terhadap environmental disclosure sedangkan leverage tidak berpengaruh terhadap environmental disclosure.
\end{abstract}

Kata kunci : profitabilitas, leverage, ukuran perusahaan, environmental disclosure.

\section{PENDAHULUAN}

Lingkungan merupakan suatu aspek yang sering dibahas dalam kegiatan ekonomi, hal ini dikarenakan dampaknya terhadap kerusakan ekosistem. Dalam rangka pencegahan hal tersebut terjadi, maka seluruh kegiatan ekonomi harus mempertimbangkan aspek lingkungan. Salah satu pelaku ekonomi yang sering dijadikan penyebab permasalahan lingkungan adalah perusahaan.

Adanya tata kelola yang baik diharapkan mampu melakukan pengawasan dan pengendalian sehingga menciptakan nilai tambah bagi perusahaan. Pencemaran lingkungan yang disebabkan oleh kegiatan perusahaan menimbulkan tekanan dari berbagai pihak khususnya masyarakat terhadap perusahaan agar memberikan informasi yang transparan mengenai aktivitas lingkungan (Anggraini, 2006). Suratno et al.(2006) menyatakan bahwa environmental disclosure tersebut dapat diungkapkan dalam Laporan Tahunan (annual report) perusahaan yang meliputi pengendalian terhadap polusi, pencegahan atau perbaikan terhadap kerusakaan lingkungan dan konservasi alam. Suratno et al. (2006) dalam penelitiannya mengungkapkan bahwa dampak negatif yang disebabkan oleh aktifitas perusahaan mengalami peningkatan permasalahan dalam hal pencemaran lingkungan hidup. Pertiwi dan Chariri (2013) juga mengungkapkan bahwa perusahaan dapat memperlihatkan kepedulian dan tanggung jawab terhadap lingkungan melalui environmental disclosure.

Berdasarkan data Wahana Lingkungan Hidup Indonesia (WALHI) Tahun 2017 bahwa selama 5 tahun terakhir terdapat 30 perusahaan berada di kawasan Dayeuhkolot, Kabupaten Bandung, Provinsi Jawa Barat, Indonesia membuang limbah ke aliran sungai Citepus. Tindakan tersebut mengakibatkan polusi air dan menjadikan penyakit warga sekitar. Di sisi lain VOA 
Indonesia (2017) mengungkapkan bahwa permasalahan pencemaran lingkungan masih terjadi di Kabupaten Sidoarjo Provinsi Jawa Timur yang selama 11 tahun masih mengancam lingkungan dan kesehatan warga sekitar yang diakibatkan oleh lumpur yang bercampur gas sulfur.

Adanya permasalahan pencemaran tersebut, Pratiwi dan Chariri (2013) yang menyatakan bahwa dunia usaha memiliki paradigma baru yang semula profit oriented only berubah menjadi Triple-P-Bottom Line yakni profit, Planet dan People. Point pokok yang harus diperhatikan dalam konsep Triple Bottom Line seperti yang diungkapkan oleh Elkington (1997) yaitu selain kondisi keuangan, perusahaan juga harus bertanggung jawab untuk menjaga bumi. Pemerintah Indonesia telah mengeluarkan peraturan terkait dengan pengungkapan sosial dan lingkungan yakni UndangUndang Nomor 40 Tahun 2007 tentang Perseroan Terbatas. Dalam Undang-Undang tersebut menyatakan bahwa perusahaan wajib melaporkan pelaksanaan tanggung jawab sosial dan lingkungannya.

$\begin{array}{llr}\text { Adanya } & \text { pergeseran } & \text { paradigma tersebut, } \\ \text { seyogyanya } & \text { perusahaan } & \text { melaporkan dan }\end{array}$
mempertanggungjawabkan masalah sosial dan lingkungan di dalam annual report (Murwaningsari, 2009). Frimpong dan Owusu (2012) menjelaskan bahwa environmental disclosure memiliki potensi untuk bertindak sebagai alat menejemen risiko yang berguna untuk menilai kepatuhan dengan peraturan perundangundangan yang ada. Hal yang sama juga diungkapkan oleh Pratama, Gallus dan Rahardja (2014) bahwa perusahaan harus memperlihatkan kepedulian dan tanggung jawab terhadap lingkungan (environmental disclosure) dengan tujuan untuk menjaga reputasi dan terhindar dari penolakan masyarakat.

Environmental disclosure juga dipengaruhi oleh suatu karakteristik perusahaan. Sebagaimana dinyatakan oleh Marwata (2001) bahwa karakteristik perusahaan dapat berupa ukuran perusahaan, profitabilitas, jumlah pemegang saham, leverage, likuiditas, jenis industri, serta profil dan karakteristik lainnya. Proksi penelitian ini menggunakan profitabilitas, leverage dan ukuran perusahaan. Adanya fenomena tersebut di atas, penelitian ini bertujuan untuk mengetahui pengaruh karakteristik perusahaan yakni profitabilitas, leverage dan ukuran perusahaan terhadap environmental disclosure pada perusahaan manufaktur yang terdaftar di Bursa Efek Indonesia (BEI) tahun 2012-2016.

\section{KAJIAN TEORI DAN PENGEMBANGAN HIPOTESIS}

Teori Agensi

Widjaja dan Magviroh (2011) menjelaskan bahwa teori keagenan menjelaskan tentang pola hubungan dua pihak yang memiliki kepentingan yang berbeda, yaitu principal (pemegang saham) dan agent (manajer). Lukviarman (2016) mengungkapkan bahwa keinginan yang berbeda tersebut membuat principal membutuhkan mekanisme untuk senantiasa memonitor agent. Perbedaan kepentingan kedua belah pihak tersebut menyebabkan ketidakseimbangan informasi yang akan memicu adanya asimetri informasi.

\section{Teori Legitimasi}

Suhardjanto (2010) menyatakan bahwa teori legitimasi digunakan untuk menjelaskan tentang environmental disclosure. Dowling dan Pfeffer (1975) menjelaskan bahwa organisasi dapat terus berjalan jika masyarakat merasa organisasi telah beroperasi dalam batas-batas sistem nilai yang dapat diterima. Secara spesifik, Cho dan Patten (2007) menyatakan teori legitimasi menyiratkan bahwa environmental disclosure merupakan fungsi dari intensitas tekanan masyarakat dan politik yang dihadapi oleh perusahaan mengenai kinerja lingkungan. Agar terhindar dari tuntutan masyarakat, Paratama et al. (2014) menyebutkan perusahaan harus memberikan informasi lingkungan yang lebih banyak melalui annual report.

\section{Teori Signaling}

Suwardjono (2010) mengungkapkan bahwa teori signal merupakan sinyal-sinyal informasi yang dibutuhkan oleh investor untuk mempertimbangkan dan menentukan para investor dalam berinvestasi kepada perusahaan. Sinyal tersebut dapat berupa inside information seperti kebijakan perusahaan yang tidak disediakan untuk umum terefleksi dalam angka laba yang dipublikasikan melalui laporan keuangan. Signaling theory juga dapat membantu agent, principal dan pihak ekternal perusahaan mengurangi asimetri informasi dengan menghasilkan kualitas informasi keuangan (Jama'an, 2008).

\section{Karakteristik Perusahaan}

Marwata (2001) menyebutkan karakteristik perusahaan merupakan ciri khusus yang menandai sebuah perusahaan berbeda dengan yang lainnya 
berdasarkan jenis usaha, pangsa pasar, sumber daya, ukuran perusahaan, profitabilitas, leverage dan karakteristik lainnya. Mirfazil dan Nurdiono (2007) menyebutkan bahwa tingginya karakteristik perusahaan mempengaruhi dampak lingkungan yang pada akhirnya akan menjadikan semakin tinggi pula tuntutan masyarakat terhadap environmental disclosure. Aljifri et al. (2014) juga menyampaikan bahwa karakteristik perusahaan merupakan sumber keunggulan kompetitif yang berguna dalam menentukan variabilitas dan kualitas pengungkapan.

\section{Environmental Disclosure}

Environmental Disclosure adalah pengungkapan informasi yang berkaitan dengan lingkungan hidup di dalam laporan tahunan perusahaan yang meliputi pengendalian terhadap polusi, pencegahan atau perbaikan terhadap kerusakaan lingkungan, dan konservasi alam (Zhegal dan Ahmed (1990) dan Suratno et al, (2006). Adanya environmental disclosure, para stakeholders dapat mengetahui aktivitas-aktivitas dan mengevaluasi kinerja perusahaan terkait lingkungan hidup melalui annual reports maupun website perusahaan (Brown dan Deegan, 1998). Suhardjanto dan Miranti, (2009) menjelaskan bahwa dengan adanya environmental disclosure diharapkan terhindar dari tuntutan masyarakat, memperoleh kepercayaan dari para stakeholders, dan menjadi perusahaan yang berkelanjutan.

\section{Profitabilitas}

Brigham dan Houston (2010) menyatakan bahwa profitabilitas adalah suatu tolak ukur yang relevan untuk menganalisa kondisi keuangan. Dalam pendapatnya, indikator untuk mengukur profitabilitas dapat melalui Gross Profit Margin, Operating Profit Margin, Net Profit Margin, Return On Investement, Return On Equity, Return On Asset, Return On Common Stock Equity dan Earning Per Share.

\section{Leverage}

Leverage menunjukkan seberapa besar penggunaan dana melalui utang (Brigham dan Houston, 2010). Menurut Nugroho (2013) leverage adalah rasio untuk mengukur berapa aktiva yang harus dibiayai oleh utang yaitu total utang terhadap rata-rata ekuitas pemegang saham. Brigham dan Houston (2010) menjelaskan bahwa indikator leverage meliputi Debt Ratio, Timed Interest earned, EBTIDA Coverage Ratio.

\section{Ukuran Perusahaan}

Ukuran perusahaan dapat diartikan sebagai besar kecilnya perusahaan dilihat dari besarnya nilai equity, nilai perusahaan, ataupun hasil nilai total aktiva dari suatu perusahaan (Subekti, 2000). Undang-undang No.20 Tahun 2008 tentang Usaha Mikro, Kecil dan Menengah pasal 1 dijelaskan bahwa "Usaha besar adalah kegiatan ekonomi produktif yang dilakukan oleh perusahaan dengan jumlah aset bersih lebih besar dari bisnis menengah.

\section{Profitabilitas dan Environmental Disclosure}

Ebiringa (2013) dan Vasanth (2015) mengatakan bahwa profitabilitas mempengaruhi environmental disclosure yang pada akhirnya akan meningkatkan kinerja perusahaan. Dengan begitu environmental disclosure dipercaya sebagai pendekatan manajemen untuk mengurangi tekanan sosial dan merespon kebutuhan sosial (Hackston dan Milne, 1996). Uwalomwa, et al. (2011) dan Giannarkis (2014) menjelaskan bahwa profitabilitas berpengaruh positif dan signifikan terhadap environmental disclosure. Berbeda dengan penelitian Nur dan Priantinah (2012) yang menyatakan bahwa profitabilitas tidak berpengaruh terhadap environmental disclosure.

Berdasarkan penjelasan diatas, maka hipotesis dalam penelitian ini dapat dirumuskan sebagai berikut :

$\mathbf{H}_{\mathbf{1}}$ : Profitabilitas berpengaruh positif dan signifikan terhadap environmental disclosure.

\section{Leverage dan Environmental Disclosure}

Naser et al. (2014) berpendapat bahwa leverage ratio berhubungan positif dengan environmental disclosure, karena perusahaan yang berisiko tinggi berusaha untuk meyakinkan investor dan kreditor dengan pengungkapan yang lebih detail. Oleh karena itu, manajemen akan secara komprehensif mengungkapkan tujuan monitoring dalam memastikan debt holders terkait dengan kemampuan membayar (Suhardjanto, 2010).

Giannarkis (2014) mengungkapkan bahwa leverage berpengaruh positif dan signifikan terhadap environmental disclosure. Pendapat lain di ungkapkan oleh Effendi et al. (2012) serta Armadi dan Astika 
(2016) bahwa leverage tidak berpengaruh terhadap environmental disclosure.

Berdasarkan penjelasan diatas, maka hipotesis dalam penelitian ini dapat dirumuskan sebagai berikut :

$\mathrm{H}_{2}$ : Leverage berpengaruh positif dan signifikan terhadap environmental disclosure.

\section{Ukuran Perusahaan dan Environmental Disclosure}

Ukuran perusahaan bisa diukur dengan menggunakan total aktiva dari suatu perusahaan (Subekti, 2000). Perusahaan besar berada dalam tekanan untuk mengungkapkan aktivitas bisnis dikarenakan aktivitas perusahaan yang berdampak kepada lingkungan sekitar (Suhardjanto et al., 2008). Oleh karena itu, environmental disclosure akan banyak dilakukan oleh perusahaan yang mempunyai omset yang besar (Despina, 2011). Rouf (2010), Giannarkis (2014), dan Brugwal dan Viera (2014) menjelaskan bahwa ukuran perusahaan berpengaruh positif dan signifikan terhadap environmental disclosure. Bertolak belakang dengan Oktariani dan Mimba (2014) yang mneyatakan bahwa ukuran perusahaan tidak berpengaruh terhadap environmental disclosure.

Berdasarkan penjelasan diatas, hipotesis dalam penelitian ini dapat dirumuskan sebagai berikut :

$\mathbf{H}_{3}$ : Ukuran perusahaan berpengaruh positif dan signifikan terhadap environmental disclosure.

\section{METODE PENELITIAN}

\section{Metode Pengumpulan Data}

Data yang digunakan pada penelitian ini adalah data sekunder yang berasal dari annual report. Populasi yang digunakan adalah seluruh perusahaan manufaktur yang terdaftar di BEI periode tahun 2012 sampai dengan tahun 2016.Alasan peneliti memilih perusahaan manufaktur karena perusahaan manufaktur mendominasi kegiatan industri yang sering berhadapan dengan kerusakan lingkungan (Kartadjumena et al. (2011). Penelitian ini menggunakan metode purposive sampling. Adapun kriteria yang digunakan untuk pemilihan sampel yakni:

1. Perusahaan manufaktur yang terdaftar di BEI periode tahun 2012 sampai dengan 2016.

2. Perusahaan manufaktur yang menerbitkan annual report periode tahun 2012 sampai dengan 2016.

3. Perusahaan manufaktur menyediakan informasi environmental disclosure.
4. Perusahaan manufaktur yang memiliki profitabilitas positif.

\section{Metode Analisis Data}

Teknik pengolahan dan penganalisisan data menggunakan software SPSS Versi 16.0. Data diolah dengan menggunakan metode data panel yaitu menggabungkan jenis data cross section dan data time series. Metode analisis yang digunakan untuk menguji hipotesis dalam penelitian ini adalah regresi berganda (multiple regression analysis). Statistik deskriptif dan uji asumsi klasik dilakukan sebelum uji hipotesis dilakukan. Uji hipotesis dilakukan dengan menggunakan koefisien determinasi (R2), Uji signifikansi parsial (uji T), uji signifikansi simultan (Uji F) dan uji regresi berganda.

\section{Definisi Operasional Variabel dan Pengukuran Variabel \\ Environmental Disclosure}

Menurut Zhegal dan Ahmed (1990) dan Suratno et al. (2006), environmental disclosure adalah pengungkapan informasi yang berkaitan dengan lingkungan hidup di dalam laporan tahunan perusahaan yang meliputi pengendalian pada polusi, pencegahan atau perbaikan kerusakan lingkungan, konservasi alam dan lain-lain. Environmental disclosure diproksikan dengan menggunakan skor pengungkapan environmental disclosure pada annual report perusahaan.

Skor diberikan pada setiap item pengungkapan aktivitas lingkungan hidup yang terdapat dalam annual report. Teknik pengukuran menggunakan pedoman GRI 4 (Global Reporting Index) ada 46 item pengungkapan lingkungan, setiap masing-masing isu lingkungan yang diungkapkan di beri skor 1 dan yang tidak mengungkapkan diberi nilai 0 atau disebut dengan teknik disclosure scoring (Al Tuwaijri, Christensen dan Hughes, 2003).

$$
\mathrm{ED}=\frac{\sum \text { item yang diungkapkan }}{\sum \text { pengungkapan lingkungan GRI }}
$$

\section{Profitabilitas}

Profitabilitas merupakan indikator kinerja yang dilakukan manajemen dalam mengelola kekayaan perusahaan dan menghasilkan laba untuk meningkatkan nilai perusahaan (Suhardjanto, 2010). Dalam penelitian ini indikator pengukuran variabel profitabilitas 
menggunakan ROA (Return On Asset), rasio ini merupakan rasio keuntungan bersih setelah pajak terhadap jumlah aset secara keseluruhan Akrout dan Othman (2013) dengan rumus sebagai berikut :

$$
\mathrm{ROA}=\frac{\text { Laba Bersih Setelah Pajak }(\mathrm{EAT})}{\text { Total Aset }}
$$

\section{Leverage}

Naser et al. (2014) berpendapat bahwa leverage ratio berhubungan positif dengan pengungkapan lingkungan, karena perusahaan yang berisiko tinggi berusaha untuk meyakinkan investor dan kreditor dengan pengungkapan yang lebih detail. Leverage merupakan pengukuran besarnya aktiva yang dibiayai dengan utang (Suhardjanto, 2010). Dalam penelitian ini, indikator pengukuran leverage mengadopsi dari penelitian dari Freedman dan Jaggi (2005) dan Akrout dan Othman (2013) dengan menggunakan rumus sebagai berikut :

$$
\text { Leverage }=\frac{\text { Total Hutang }}{\text { Total Aset }}
$$

\section{Ukuran Perusahaan}

Ukuran perusahaan dapat diartikan sebagai besar kecilnya perusahaan dilihat dari besarnya nilai equity, nilai perusahaan, ataupun hasil nilai total aktiva dari suatu perusahaan (Subekti, 2000). Dalam penelitian ini, indikator pengukuran ukuran perusahaan mengadopsi penelitian dari Freedman dan Jaggi (2005), Haniffa dan Cooke (2005), dan Suhardjanto (2008) yaitu total aset ditransformasikan dalam bentuk logaritma dengan tujuan untuk menyamakan dengan variabel lain. Penggunaan ukuran perusahaan dengan logaritma dilakukan karena lebih dapat mencerminkan nilai ukuran perusahaan Haniffa dan Cooke (2005) dengan menggunakan rumus sebagai berikut :

SIZE $=\log$ (nilai buku total aset $)$

\section{HASIOL DAN PEMBAHASAN}

Prasyarat pengujian regresi berganda dilakukan uji asumsi klasik untuk memastikan bahwa data penelitian valid, tidak bias, konsisten dan penaksiran koefisien regresinya efisien (Gujarati, 2003). Pengujian asumsi klasik meliputi: normalitas, multikolinieritas, autokorelasi dan heteroskedastisitas. Penelitian ini telah lolos uji asumsi klasik sebagai prasyarat pengujian regresi berganda. Persamaan model regresi yang dipergunakan dalam penelitian ini adalah sebagai berikut:

$$
Y=\beta_{0}+\beta_{1} X_{1}+\beta_{2} X_{2}+\beta_{3} X_{3}+\epsilon
$$

$\mathrm{Y}:$ Environmental disclosure

$\beta_{0}$ : Konstanta

$\beta_{1,2,3}$ : Koefisien regresi berganda masing-masing

Berikut merupakan hasil pengujian regresi

\begin{tabular}{|c|c|c|c|c|}
\hline Variabel & & Koefisien & $\mathbf{T}$ & Sig. \\
\hline (Constant) & & -0.153 & $-2,382$ & 0,019 \\
\hline Profitabilitas & & 0,147 & 1,781 & $0,077 * *$ \\
\hline Leverage & & $-0,061$ & $-0,830$ & 0,408 \\
\hline Ukuran & & 0,122 & 1,805 & $0,073 * *$ \\
\hline \multicolumn{5}{|l|}{ Perusahaan } \\
\hline R Square & & 0,068 & & \\
\hline Adjusted & $\mathrm{R}$ & 0,048 & & \\
\hline \multicolumn{5}{|l|}{ Square } \\
\hline $\mathrm{F}$ & & 3,379 & & \\
\hline Sig. & & $0,020^{*}$ & & \\
\hline
\end{tabular}
berganda penelitian ini :

Table 4.1 Hasil Analisis Regresi Berganda

Sumber: Olah data SPSS, 2018

*Secara statistic signifikansi pada tingkat 5\%

**Secara statistic signifikansi pada tingkat $10 \%$

Table $4.1 \mathrm{di}$ atas menunjukkan bahwa nilai $\mathrm{R}$ Square $\left(\mathrm{R}^{2}\right)$ sebesar 0,068 dan adjusted $R$ Square (Adjusted $\mathrm{R}^{2}$ ) sebesar 0,048. Berdasarkan nilai adjusted $\mathrm{R}^{2}$ tersebut disimpulkan bahwa sebanyak $4 \%$ variable dependen dapat dijelaskan oleh variable independen dan sisanya sebanyak $96 \%$ dijelaskan oleh factor lain. Nilai F hitung sebesar 3,379 dengan probabilitas 0,020 (probabilitas <0,05). Hal ini menunjukkan bahwa variable-variabel independen secara bersama-sama berpengaruh terhadap environmental disclosure.

Berdasarkan table 4.1 di atas juga menunjukkan bahwa variable - variable independen yang berpengaruh posisif signifikan terhadap variable dependen adalah profitabilitas dan ukuran perusahaan pada tingkat signifikansi 0,10 . Namun, leverage tidak berpengaruh terhadap variable dependen.

\section{Pengujian Hipotesis 1: Profitabilitas Berpengaruh Positif Dan Signifikan Terhadap Environmental Disclosure.}

Hipotesis 1 menyatakan bahwa profitabilitas berpengaruh positif dan signifikan terhadap 
environmental disclosure. Hasil penelitian ini sesuai dengan Uwalomwa, et al. (2011) dan Giannarkis (2014) yang menjelaskan bahwa profitabilitas berpengaruh positif dan signifikan terhadap environmental disclosure. Namun, hasil penelitian ini bertentangan dengan penelitian sebelumnya yang dilakukan oleh Davey (1982), Singh dan Ahuja (1983), Robert (1992), Hackston dan Milne (1996) dan Nur dan Priantinah (2012) yang menyatakan bahwa profitabilitas tidak berpengaruh terhadap environmental disclosure.

Pengujian Hipotesis 2: Leverage berpengaruh positif dan signifikan terhadap environmental disclosure.

Hipotesis 2 menyatakan bahwa leverage berpengaruh positif dan signifikan terhadap environmental disclosure. Hasil Penelitian ini menyatakan bahwa Leverage tidak berpengaruh terhadap environmental disclosure. Hal ini sesuai dengan penelitian Belkaoui dan Karpik (1989), Scott (1997), Cornier dan Magnam (1999) dan Anggraini (2006) yang menyatakan pengaruh negative signifikan antara kedua variable tersebut. Sesuai teori agensi bahwa koefisien negative menunjukkan bahwa tingkat leverage yang tinggi akan mengurangi pengungkapan tanggung jawab social yang dibuatnya agar tidak menjadi sorotan dari para debtholders. Dengan tingkat leverage yang tinggi kemungkinan besar perusahaan akan mengalami pelanggaran terhadap kontrak utang sehingga manajer akan berusaha untuk melaporkan laba sekarang lebih tinggi dibandingkan laba masa depan. Laba yang dilaporkan lebih tinggi akan mengurangi kemungkinan perusahaan melanggar perjanjian utang. Manajer akan memilih metode akuntansi yang akan memaksimalkan laba sekarang. Menurut Belkaoui dan Karpik (1989) keputusan untuk mengungkapkan informasi social akan mengikuti pengeluaran pengungkapan yang pada akhirnya akan menurunkan pendapatan. Oleh karena itu, semakin tinggi tingkat leverage semakin besar kemungkinan perusahaan akan melanggar perjanjian kredit sehingga perusahaan akan berusaha melaporkan laba sekarang lebih tinggi.

Naser et al. (2014) berpendapat bahwa leverage ratio berhubungan positif dengan environmental disclosure dikarenakan perusahaan yang berisiko tinggi berusaha untuk meyakinkan investor dan kreditor dengan pengungkapan yang lebih detail. Oleh karena itu, manajemen akan secara komprehensif mengungkapkan tujuan monitoring dalam memastikan debt holders terkait dengan kemampuan membayar (Suhardjanto, 2010). Hal yang sama juga diungkapkan oleh Giannarkis (2014) bahwa leverage berpengaruh positif dan signifikan terhadap environmental disclosure. Pendapat lain di ungkapkan oleh Effendi et al. (2012) serta Armadi dan Astika (2016) bahwa leverage tidak berpengaruh terhadap environmental disclosure.

\section{Pengujian Hipotesis 3: Ukuran Perusahaan Berpengaruh Positif Dan Signifikan Terhadap Environmental Disclosure.}

Hipotesis 3 menyatakan bahwa ukuran perusahaan berpengaruh positif dan signifikan terhadap environmental disclosure. Hasil penelitian ini menunjukkan bahwa ukuran perusahaan perusahaan berpengaruh positif dan signifikan terhadap environmental disclosure. Hasil ini sesuai dengan penelitian Rouf (2010), Giannarkis (2014), dan Brugwal dan Viera (2014) yang menjelaskan bahwa ukuran perusahaan berpengaruh positif dan signifikan terhadap environmental disclosure. Namun, hasil penelitian ini bertentangan dengan penelitian sebelumnya yang dilakukan oleh Davey (1982), Singh dan Ahuja (1983), Robert (1992), Hackston dan Milne (1996), dan Oktariani dan Mimba (2014) yang menyatakan bahwa ukuran perusahaan tidak berpengaruh terhadap environmental disclosure.

\section{KESIMPULAN DAN SARAN \\ Kesimpulan}

Berdasarkan hasil penelitian yang telah dibahas sebelumnya maka kesimpulan penelitian ini adalah sebagai berikut:

1. Profitabilitas berpengaruh positif dan signifikan terhadap environmental disclosure.

2. Leverage tidak berpengaruh terhadap environmental disclosure.

3. Ukuran perusahaan berpengaruh positif dan signifikan terhadap environmental disclosure.

\section{Keterbatasan}

1. Penelitian ini hanya menggunakan perusahaan manufaktur, penelitian selanjutnya akan lebih baik menambahkan sampel perusahaan perbankan yang terdaftar di BEI.

2. Penelitian ini hanya menggunakan annual report selama 5 tahun (2012-2016), sebaiknya penelitian selanjutnya menambah periode tahun annual report. 


\section{DAFTAR PUSTAKA}

Akrout, M M dan Othman, H B. 2013. A study of the determinants of corporate environmental disclosure in MENA emerging markets. Journal of Reviews on Global Economics, 2: $46-59$.

Aljifri, Khaled., Abdulkareem Alzarouni., Chew Ng., dan Mohammad Iqbal Tahir. 2014. The Association Between Firm Characteristics and Corporate Financial Disclosures: Evidence from UAE Companies. The International Journal of Business and Finance Research, 8 (2): 101-123.

Anggraini, Fr. Reni Retno. 2006. Pengungkapan Informasi Sosialdan Faktor- Faktor yang Mempengaruhi Pengungkapan Informasi Sosial dalam Laporan Keuangan Tahunan: Studi Empiris pada PerusahaanPerusahaan yang Terdaftar di Bursa Efek Jakarta. Simposium Nasional Akuntansi 9, Padang. Hal: 1-21.

Armadi, I Wayan., dan Astika, Ida Bagus Putra. 2016. Pengaruh Profitabilitas, Leverage dan Ukuran Perusahaan pada Nilai Perusahaan Melalui Pengungkapan Tanggung Jawab Sosial. E-Jurnal Akuntansi Universitas Udayana, 17 (1): $233-256$.

Burgwal, D. v. d., dan R. J. O. Vieira. 2014. Environmental Disclosure Determinants in Dutch Listed Companies. Revista Contabilidade and Financas, 25 (64): 60 78.

Brigham dan Houston. 2010. Dasar-dasar Manajemen keuangan Buku 1 Edisi 11. Salemba Empat: Jakarta.

Brown, N. dan Deegan, C. 1998. The Public Disclosure of environmental Performance Information - a Dual Test of Media Agenda Setting Theory and Legitimacy Theory. Accounting, Auditing and Accountability Journal 9: $52-69$.

Cho, C. H. dan D. M. Patten. 2007. The Role of Environmental Disclosures as Tools of Legitimacy: A Research Note. Accounting, Organizations and Society, 32 (7): 639647.

Dowling, J. dan Pfeffer, J. 1975. Organisational Legitimacy: Social Values and Organisational Behavior, Pacijic Sociological Review 18 : 122-136.

Ebiringa O.T., Emeh Yadirichukwu., E. E. Chigbu dan Obi Joseph Ogochukwu. 2013. Effect of Firm Size and Profitability on Corporate Social Disclosures: The Nigerian Oil and Gas sector in Focus. British Journal of
Economics, Management and Trade, 3(4): 563-574.

Effendi, B., Uzliawati, L., dan Yulianto, A. S. 2012. Pengaruh Dewan Komisaris terhadap Environmental Disclosure pada Perusahaan Manufaktur yang Listing di BEI Tahun 2008-2011. Simposium Nasional Akuntansi $X V$. Banjarmasin.

Elkington, J. 1997. Cannibal with Forks, the Tripple Bottom Line of Twentieth Century Business. Capstone Publishing Ltd: London.

Freedman, M., dan B. Jaggi. 2005. Global Warming, Commitment to The Kyoto Protocol, and Accounting Disclosures by The Largest Global Public Firms from Polluting Industries. The International Journal of Accounting 40: 215- 232.

Owusu, C dan Frimpong, S. 2012. Corporate Social and Environmental Auditing: Perceived Responsibility or Regulatory Requirement?. Research Journal of Finance and Accounting, 3 (4): 47-57.

Ghozali, Imam. 2011. Aplikasi Analisis Multivariate dengan Program SPSS. Semarang: Badan Penerbit Universitas Diponegoro.

Giannarkis, G., 2014. Corporate Governance and Financial Characteristic Effect on The Extent of Corporate Social Responbility Disclosure. Social Responbility Journal, 10 (4): 569-590.

Hackston, David. dan Markus J. Milne. 1996. Some Determintants of Social and Enviromental Disclosures in New Zealand Companies. Accounting, Auditing and Accountability Journal, 9 (1): $: 77$ - 108.

Haniffa, R.M., Cooke, T.E. 2005. The Impact Of Culture And Governance On Corporate Social Reporting. Journal of Accounting and Public Policy, 24 : 391 - 430.

Jama'an. 2008. Pengaruh Mekanisme Corporate Governance, dan Kualitas Kantor Akuntan Publik Terhadap Integritas Informasi Laporan Keuangan (Studi Kasus Perusahaan Publik yang Listing di BEJ). Jurnal Akuntansi dan Keuangan, Universitas Diponegoro, Semarang.

Kartadjumena, Eriana., Dudi Abdul Hadi., dan Novan Budiana. 2011. The Relationship of Profit and Corporate Social Responsibility Disclosure (Survey on Manufacture Industry in Indonesia). 2nd International Conference on Business and Economic Research (2nd ICBER 2011) Proceeding. 
Latan, Hengky. 2014. Aplikasi Analis Data Statistik Untuk Ilmu Sosial Sains dengan IBM SPSS. Bandung: Alfabeta.

Lukviarman, Niki. 2006. Dasar Dasar Manajemen Keuangan. Padang: Andalas University Press.

Marwata. 2001. Hubungan Antara Karakteristik Perusahaan dan Kualitas Ungkapan Sukarela Dalam Laporan Tahunan Perusahaan Publik di Indonesia. Simposium Nasional Akuntansi IV. Bandung: 155-172

Mirfazli, E., dan Nurdiono. 2007. Evaluasi Pengungkapan Informasi Pertanggungjawaban Sosial Pada Laporan Tahunan Perusahaan Dalam Kelompok Aneka Industri Yang Go Publik di BEJ. Jurnal Akuntansi dan Keuangan 12: 1 45.

Murwaningsari, Etty. 2009. Hubungan Corporate Governance, Corporate Social Responsibility dan Corporate Financial Performance dalam Satu Continum. Jurnal Akuntansi dan Keuangan Universitas Trisakti, 11 (1).

Nashear, Dila. 2017. Miris, 30 Pabrik di Dayeuhkolot Buang Limbah ke Sungai. Diakses 27 Februari 2018. https://daerah.sindonews.com/read /1193865/21/miris-30-pabrik-didayeuhkolot-buang-limbah-ke-sungai1491212988.

Nasir, Azwir., Elfi Ilham,. dan VadelaIrna Utara. 2014. Pengaruh Karakteristik Perusahaan dan Corporate Governance terhadap Pengungkapan Sustainability Report pada Perusahaan LQ45 yang Terdaftar. Jurnal ISSN 0853-7593, 22(1).

Nur, Marzully, dan Denies Priantinah. 2012. Analisis Faktor-Faktor yang Mempengaruhi Pengungkapan Corporate Social Responsibiity di Indonesia (Studi Empiris Pada Perusahaan Berkategori High Profile yang Listing di Bursa Efek Indonesia). Jurnal Nominal, 1 (1): 22 - 34.

Riski, Petrus. 2017. Lumpur Lapindo 11 Tahun: Masalah Lingkungan dan Kesehatan Masih Ancam Warga. Diakses 27 Februari 2018. https://www.voaindonesia.com/a/lumpurlapindo-11-tahun-masalah-lingkungandan-kesehatan-masih-ancamwarga/3875373.html.

Pratiwi, Kurnia Putri dan Anis Chariri. 2013. Environmental Incident, Pemberitaan Media dan Praktik Pengungkapan
Lingkungan (Environmental Disclosure): Studipada Sustainability Report Asia Pulp And Paper Co., Ltd. Diponegoro Journal of Accounting, Fakultas Ekonomika dan Bisnis.

Oktarina, Ni Wayan dan Ni Putu Sri Harta Mimba. 2014. Pengaruh Karakteristik Perusahaan dan Tanggung Jawab Lingkungan pada Pengungkapan Tanggung Jawab Sosial Perusahaan. E-JurnalAkuntansi Universitas Udayana, 6 (3): 402 - 418.

Pratama, Agny Gallus, dan Rahardja. 2013. Pengaruh Good Corporate Governance dan Kinerja Lingkungan terhadap Pengungkapan Lingkungan (Studi Empiris pada Perusahaan Manufaktur dan Tambang yang Terdaftar pada Bursa Efek Indonesia (BEI) dan Termasuk dalam PROPER Tahun 2009-2011). Diponegoro Journal of Accounting, 2 (3): 1 - 14.

Rouf, Md. A. 2010. Corporate Characteristics, Governance Attributes and The Extent Of Voluntary Disclosure In Bangladesh. Asian Journal of Management Research. Online Open Access publishing platform.

Subekti, Imam dan Indra Kusuma. 2000. Asosiasi antara Set Kesempatan Investasi dengan Kebijakan Dividen Perusahaan, serta Implikasinya pada Perubahan Harga Saham. Simposium Nasional Akuntansi III,

Suhardjanto. 2008. Environmental Reporting Practies: An Evidence From Indonesia. Jurnal Akuntansi dan Bisnis, 8 (1): 33 - 46.

Suhardjanto, Djoko. 2010. Corporate Governance, Karakteristik Perusahaan dan Environmental Disclosure. Prestasi Fakultas Ekonomi Universitas Sebelas Maret, 6 (1) : ISSN 1411-1497.

Suhardjanto, D., dan Miranti, L. 2009. Praktik Penerapan Indonesian Environmental Reporting Index dan Kaitannya Dengan Karakteristik Perusahaan. JAAI, 13 (1): 63 -67 .

Suhardjanto, D., Tower G., dan Brown., A.M. 2007. Generating A Uniquely Indonesian Environmental Reporting Disclosure Index Using Press Coverage as An Important Proxy of Stakeholder Demand. Paper Submission to Asian Academic Accounting Association Annual Conference. Yogyakarta, Indonesia.

Suratno, Darsono., dan Siti Mutmainah. 2006. Pengaruh Environmental Performance terhadap Environmental Disclosure dan Economic Performance: Studi Empiris pada 
Perusahaan Manufaktur yang Terdaftar Di Bursa Efek Jakarta Periode 2001-2004.

Simposium Nasional Akuntansi IX. Padang.

Suwardjono. 2010. Teori Akuntansi: Pengungkapan dan Sarana Interpretatif. Edisi Ketiga. BPFE, Yogyakarta.

Vasanth, V., Selvam, M., Lingaraja, K., dan Ramkumar, R.R. 2015. Nexus between Profitability and Environmental Performance of Indian Firms: An Analysis with Granger Causality. International Journal of Energy Economics and Policy, 5(2): 433-439.

Uwuigbe, Uwalomwa Nil., Ben-Caleb Egbide., dan Akanbi Moses Ayokunle. 2011. The Effect of Board Size and Board Composition on Firms Corporate Environmental Disclosure: A Study of Selected Firms in
Nigeria. Acta Universitatis Danubius, 7 (5): $164-176$

Republik Indonesia Undang-Undang Perseroan Terbatas No. 40Tahun 2007 Tentang perseroan terbatas.

Republik Indonesia. 2008. Undang-undang No.20 Tahun 2008 tentang Usaha Mikro, Kecil dan Menengah.

Widjaja, F P dan R E Maghviroh. 2011. Analisis Perbedaan Kualitas Laba dan Nilai Perusahaan Sebelum dan Sesudah Adanya Komite pada Bank-Bank Go Public di Indonesia. The Indonesia Accounting Review, 1 (2): 117-134.

Zeghal, Daniel and Sadrudin A. Ahmed. 1990. Comparison of Social Responsibility Information Disclousure Media Used by Canadian Firms. Accounting, Auditing and Accountability Journal, 3 (1): 38 - 53. 